\title{
El libro, pasajero en clase turista The book, passenger in economy class
}

\author{
Marta Aguilar Moreno \\ Facultad de Bellas Artes \\ Universidad Complutense de Madrid. \\ España \\ maraguil@art.ucm.es \\ http://orcid.org/0000-0003-1730-9402
}

Recibido 29/10/2016

Aceptado 07/01/2017
Revisado 05/01/2017

Publicado 01/06/2017

\section{Resumen}

A modo de estrategia se van dibujando los destinos soñados, dando visibilidad a la naturaleza oculta del imaginario escondido. El libro, considerado como espacio donde se piensa, se percibe, se sueña, se vive... es el portador habitual de ideas, el contenedor de hallazgos y de presencias, es el administrador del pensamiento estético y las reflexiones más íntimas. Sirva de guía esta memoria sobre libros auto editados, unidos por hipervínculos de temática y procedencia diversa, que muestran experiencias vividas a través del viaje, primando las emociones. Un viaje tanto

\section{Abstract}

By way of a strategy dreamt of destinations are drawn giving visibility to nature hidden in the concealed imagination. The book considered as a space where one thinks, feels, dreams, lives.... is the bearer of every day ideas, the receptacle of discoveries and of presences, it is the administrator of aesthetic thought and of the most intimate reflections. This memoir serves as a guide for self edited books, united by hyperlinks through theme and from varied sources, which show experiences as lived through journeys, with emotions taking precedence. A geophysical journey as well as an interior one, where the desire to 
Revista de Estudios en Sociedad, Artes y Gestión Cultural

www.terciocreciente.com
Monográfico Extraordinario I

Julio 2017

Estudio
ISSN: 2340-9096

DOI: $10.17561 /$ rtc.mextra1.10
http://revistaselectronicas.ujaen.es/index.php/RTC geofísico como interior, donde el deseo de habitar un espacio adquiere un protagonismo considerable. La percepción del paisaje, las vivencias y reflexiones quedan latentes en cada uno de los libros referenciados inhabit a certain space acquires significant role. The perception of the landscape, the experiences and reflections remain latent in each of the referred to books.

Palabras clave / Keywords

Libro-arte; libro de artista; cuaderno de viaje; viaje; habitar

Book art; artist's book; sketchbook; journey; inhabit

Para citar este artículo

Aguilar Moreno, M. (2017). El libro, pasajero en clase turista Tercio Creciente 13, págs. 161-176. https://dx.doi. org/10.17561/rtc.mextra1.10 


\section{Introducción}

El viaje como inspiración. El paisaje como pretexto.

Documentar los relatos sobre viajes ha significado cambiar de discurso, clarificar ideas y proporcionar claves para el mejor entendimiento de los libros. Con la intención de acercar el paisaje al espectador se desvela la experiencia estética vivida y se ofrece una mirada que supuestamente predispondrá al futuro viajero.

El escribir un artículo sobre mi propio proceso de creación y los elementos, acciones o lugares que han dado forma a la materialización de mi pensamiento ha resultado un encuentro placentero con mi propia obra. El acto de contextualizar ha supuesto reconstruir el propio proceso creativo recreando lo andado y determinar los hallazgos en los que no se basa la práctica de la investigación. El carácter empírico y teórico de este trabajo nos acerca al libro de artista tomando como referente el paisaje. Agrupar los libros bajo una misma temática y con un mismo pretexto ha propiciado la narración de historias vividas desde el campo ilimitado que ofrece la gráfica contemporánea. La escritura ha favorecido la planificación. Los conceptos como portabilidad, progresión, dirección o memoria son características formales que han valido para el discurso propio de la creación con forma de libro. No olvidemos que, para reordenar el proceso creador, ha sido necesario profundizar en el archivo donde nacen las ideas y rescatar los dibujos rápidos de retentiva que se diseminan en los cuadernos de campo. Por ello considero necesario ensalzar el valor de los cuadernos, por tratarse del proceso de construcción y realización de una idea, donde el dibujo actúa como pensamiento, representación y comunicación.

\section{Con la mochila a cuestas. Los cuadernos}

La realización de un libro a partir de un viaje tiene como propósito revivir y disfrutar cada instante compartido, rememorando los lugares más significativos, más destacados y las impresiones más personales, siendo el sentido principal las distintas formas de mirar. "El libro de artista es un objeto de arte y como tal es eminentemente interdisciplinar, se abre a un sinfín de disciplinas y enfoques múltiples. Es también un libro que despierta todos los sentidos y a su vez nos ofrece la libertad creativa desnuda de quien lo concibe” (1).

Los grandes medios de comunicación masivos han llegado a los lugares más recónditos imaginados por el hombre, despertando los sentidos y el interés por penetrar en la realidad. "A través de la fantasía los libros han relatado las exploraciones más inverosímiles de todos los continentes de ficción. Los viajes requieren un tiempo y una intensidad. Pueden ser un paseo, un éxodo, una odisea, un periplo... Cada uno de ellos una aventura y una manera diferente de vivir el tiempo y el espacio" (2). Por ello, cuando emprendemos un gran viaje, parte 
Revista de Estudios en Sociedad, Artes y Gestión Cultural

www.terciocreciente.com

http://revistaselectronicas.ujaen.es/index.php/RTC
Monográfico Extraordinario I Julio 2017

Estudio esencial del equipaje es el cuaderno de campo, donde se irán recreando los instantes vividos, impresiones, emociones, lugares y gentes que dejen constancia de los momentos solazados; en cada rincón se compone una imagen digna de ser recordada ${ }^{1}$.

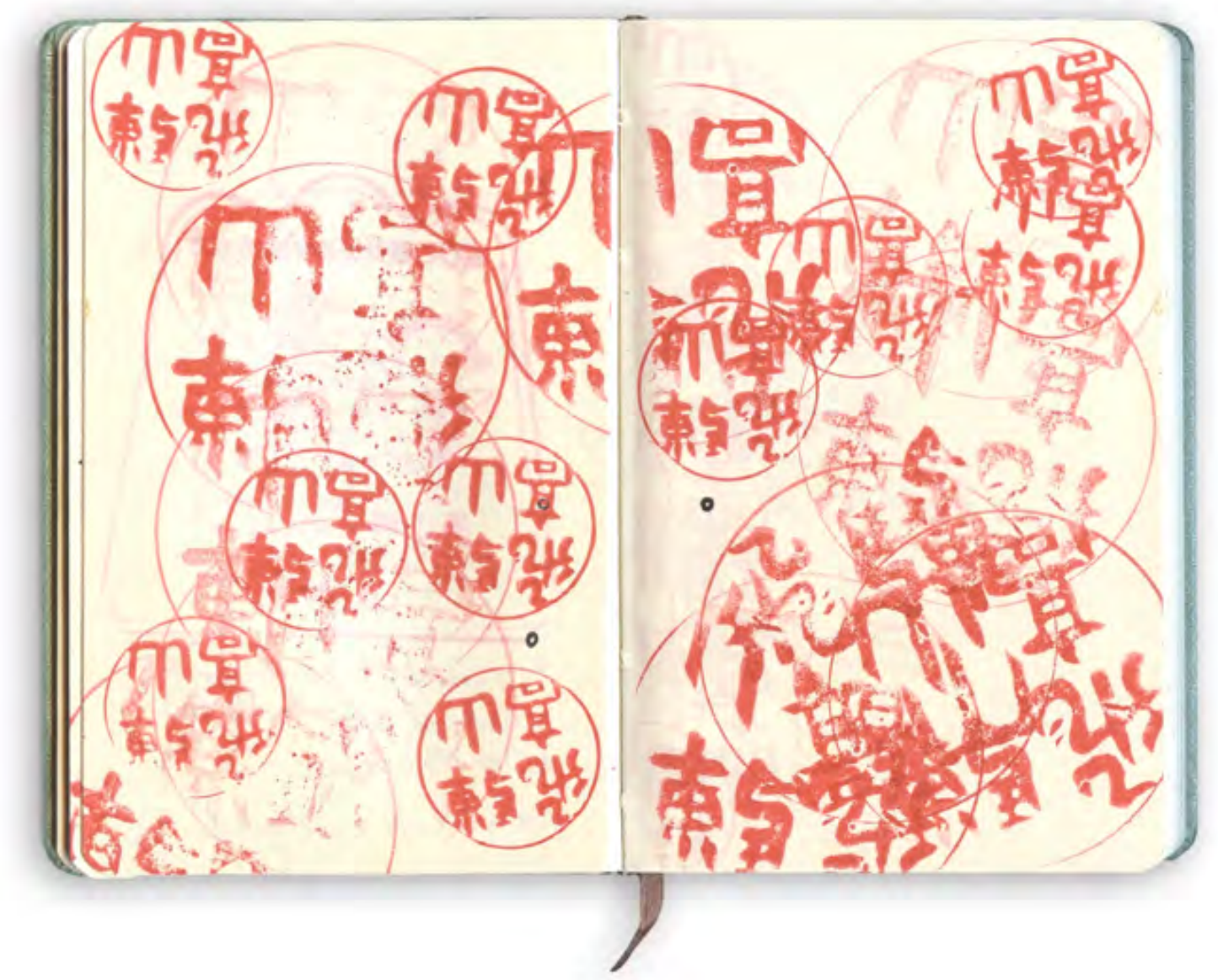

(fig. 1) Nueva línea troncal, Japón, 2008 
Estudio
Muchos de los viajes los concebimos a través de una mirilla, vamos succionando infinidad de instantes y los vamos recopilando con nuestros dispositivos digitales. Solo nos interesa capturar el momento y coleccionar instantáneas, pero esto hace que no podamos recrearnos en lo esencial: la observación y la interpretación.

A nuestro regreso, las postales viajeras serán guardadas, como imágenes secuenciadas, en el fondo de un disco duro y ni siquiera narrarán una historia coherente porque pasarán a ser un cúmulo de datos en un ordenador. Sin embargo, los cuadernos nos permiten volver atrás en el tiempo, reanudar el camino, crear procesos de construcción de discursos, cavilar sobre el viaje, redibujar lo vivido, porque la observación y la interpretación han sido el motor de su creación.

"En los cuadernos de los dibujantes están las imágenes del mundo, el diario visual y el collage tangible de la vida, la crónica instantánea de la mirada” (3). Los cuadernos

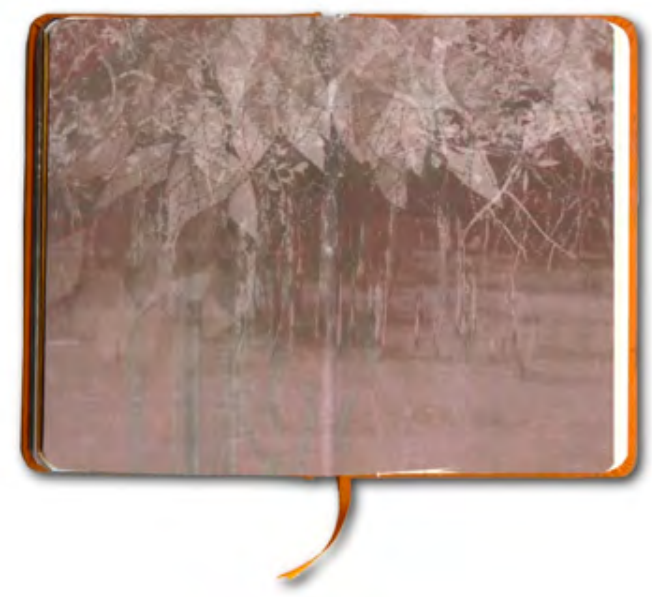

se convierten en mapas transmisores de experiencias sensoriales. La contemplación analítica sirve de soporte intuitivo para plasmar cómo evolucionan las ideas. Los cuadernos nos proporcionan las claves para comunicar visualmente y nos incitan a sustituir sus páginas por lienzos, a construir un discurso lineal, a abstraernos en un diálogo íntimo, a desarrollar un libro como estrategia de comunicación visual ${ }^{2}$.

En la mesa de trabajo está el cuaderno camboyano. Sin duda será el próximo libro. Nada más aterrizar en el sudeste asiático las visiones se materializaron en formas, colores, texturas, olores... ahora, de regreso, todo ello reside almacenado en la memoria del cuaderno convertido en el testigo de aquello que se ha visto y se ha vivido. Siempre se encuentra un momento para imaginar y transcribir las experiencias sentidas. Anotar y dibujar palabras, realizar imágenes, recortar y pegar diversos materiales, con la necesidad imperiosa de atrapar el instante. (fig. 2)

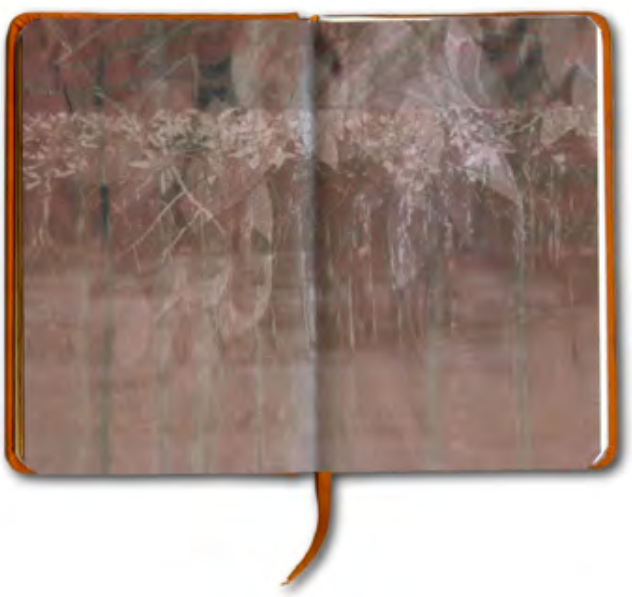

(fig. 2) Manglares en los alrededores de Sihanoukville, Camboya, 2016 
Por eso, debemos enfatizar en el proceso creativo de los artistas y su capacidad reveladora de las primeras ideas. Los bocetos son claves para el trabajo de cualquier artista. Sirven para emprender un camino y descubrir hasta dónde se puede llegar. No tienen la presión de un trabajo bien definido y permiten poner en práctica la experimentación y el hallazgo.

\section{Pero ¿Cuándo nacen los libros?}

Redescubrir los apuntes, los bocetos, los espontáneos trazos captados al instante dibujados al lado de un garabato, el trocito de papel pegado como recordatorio, el signo gráfico que perpetúa una forma, un color, acuden a nuestra memoria y surge la necesidad del relato. Después de un viaje, nuestra cabeza es un centro caótico y vivencial, la intensidad del tiempo transcurrido nos sugiere reordenar el imaginario. La necesidad de evaluar los resultados, con la intención de dar visibilidad a nuestros hallazgos, nos lleva a describir lo experimentado.

En nuestro caso, el primer contacto con el libro se realiza de un modo natural fundado en los métodos y procesos propios de las artes plásticas. El dibujo será el camino más directo para expresar el fruto de la percepción y el pensamiento visual, combinado con la gráfica sostenible basada en procesos no tóxicos, técnica empleada en la mayoría de los libros referenciados. Más tarde llegará la crónica detallada del proceso de creación convertida en narrativa visual.

Comenzaremos nuestra narración con el paisaje tal como lo conciben los naturalistas alpinos del Renacimiento. A través del revestimiento cultural del paisaje pensamos, sentimos y miramos. No necesariamente pintamos del natural, sino que el modelo nos hace pensar en él. Centrémonos en la importancia del paisaje como estética de la naturaleza. El primer libro al que haremos referencia es En el jardín te esperaré, donde una fuerte influencia oriental reproduce la toma de configuraciones concretas que se van disponiendo a lo largo del libro acordeón. La imagen de la naturaleza, el contenedor de vivencias, la sustancia geográfica física y onírica que se percibe tras un viaje por el corazón de las estepas asiáticas, nos permite descubrir el paisaje bajo el concepto de la figuración cultural, mostrando una relación directa con la belleza de la forma y su interior ${ }^{3}$. (fig. 3)

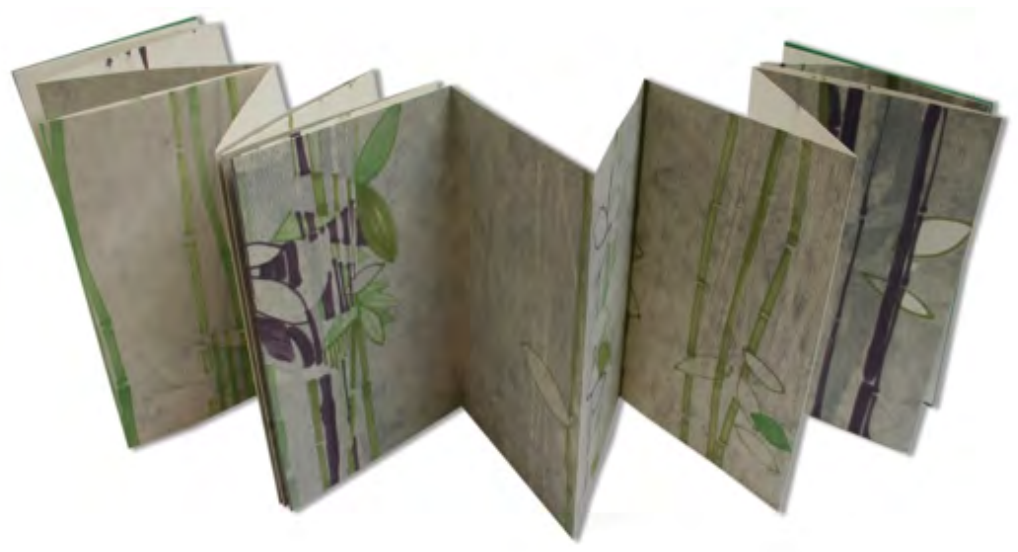

(fig. 3) En el jardín te esperaré, jardines en Suzhou, 
Rainer María Rilke decía que el pintor recibe del paisaje el lenguaje para sus confesiones. Para aprender a mirar el lenguaje creador debemos remitirnos al propio mapa cognitivo, donde algunas constantes nos conducirán por los caminos del paisaje vivido... el paisaje del alma.

El siguiente libro que tiene como protagonista el paisaje es "El bosque donde habito"4. En esta ocasión, la experiencia docente convierte al libro en un laboratorio de comunicación de experiencias y realidades sobre diferentes aspectos de nuestra vida cotidiana. El objetivo propuesto, como dinámica de grupo, fue construir relatos, a partir de diferentes dibujos y fotografías, que dieran visibilidad a las formas en las que percibimos y transformamos los espacios habitables, las formas de ocupación y construcción del mundo que nos rodea. La experiencia sirvió de excusa para recopilar los resultados y dar claridad a la propuesta, en formato libro de artista, permitiendo alcanzar los lugares con el deseo de ver, con nuestros propios ojos, lo que tantas veces hemos supuesto (5). (fig. 4)
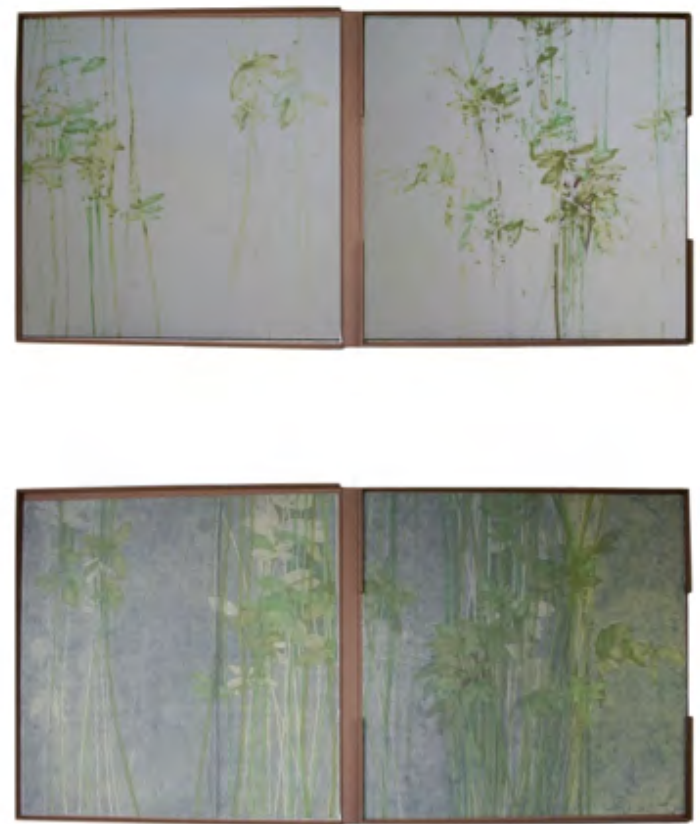

(fig. 4) El bosque donde habito, 2013 
Estudio

También el paisaje convierte a Tana Toraja en sencillamente única. Los Torajas habitan el vasto y agreste paisaje de las tierras altas del sur de Sulawesi demostrando que hay vida después de la muerte a través de sus ritos fúnebres. Un merodeo por el norte de Rantepao, base más popular para explorar el panorama de los alrededores, nos conduce a Pana. Nos adentramos en el bosque abigarrado de bambús. Un aire frio enigmático nos empuja hacia atrás. Dirigimos nuestra vista hacia arriba. De los árboles penden troncos huecos de madera envueltos en gasas y trapos húmedos. Son los sepulcros de los niños menores de dos años. Sus tumbas colgantes resultan macabras pero fascinantes ${ }^{5}$. Compartir esta experiencia subjetiva, a través de la expresión artística, lo permite el carácter interdisciplinario del libro de artista. (fig. 5)

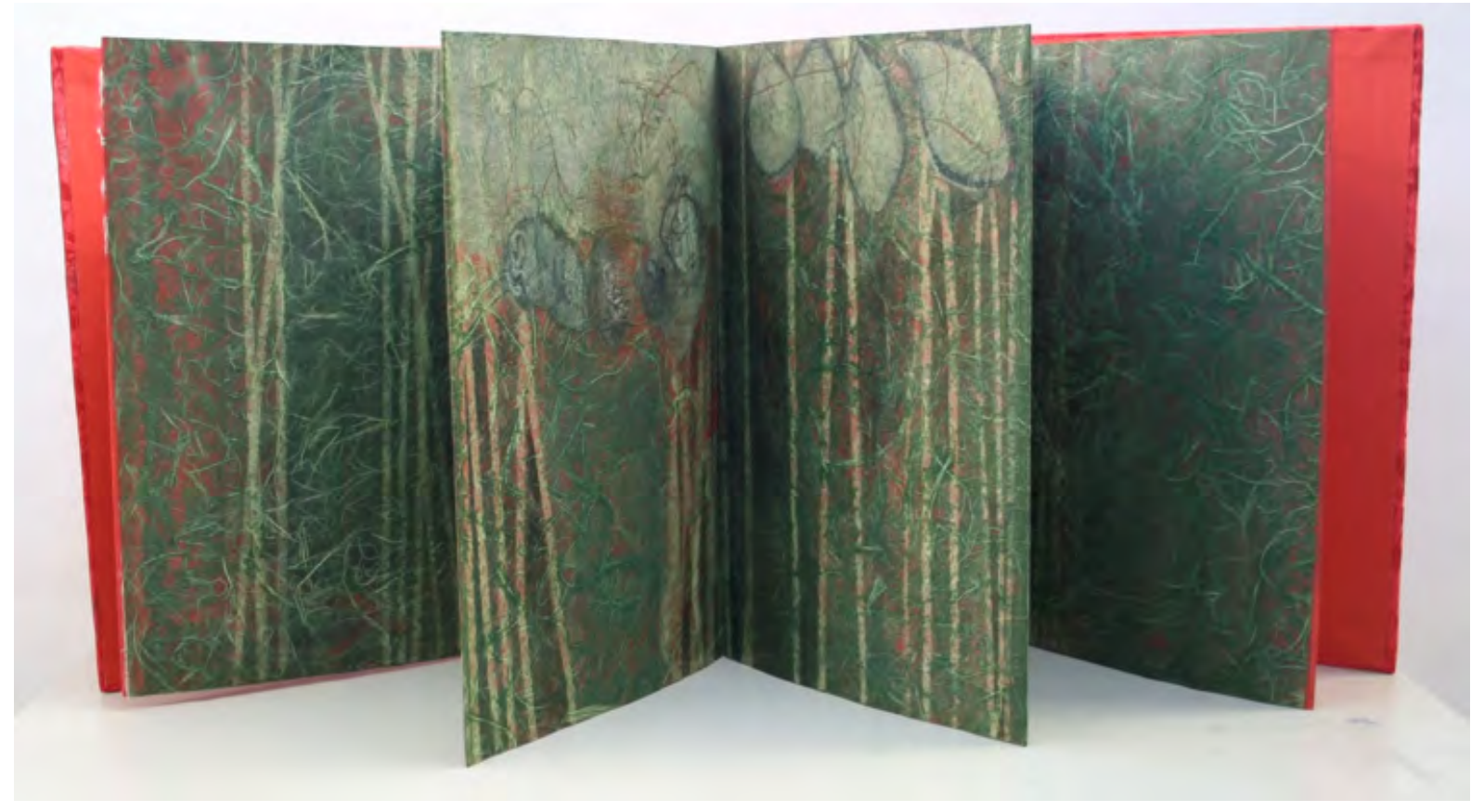

(fig. 5) El cementerio de los niños, 2013 
Estudio
El adentrarse en un paisaje desconocido supone, muchas veces, oír sonidos y ruidos nunca anteriormente escuchados. El libro En un metro de bosque, un año observando la naturaleza, de David George Haskell, nos sirve de inspiración para la narración del viaje... como si de una declaración de intenciones se tratase... y nos rememora sensaciones: "el viento en calma, no cantan los pájaros ni los insectos se descubren. Los ruidos de la actividad humana desaparecen”. El leve murmullo de la estela hacia el norte es el único ruido por defecto. Comienza el ascenso por el envolvente Delta del Mekong, nos fundimos en idílicos paisajes por tierras vietnamitas. Río arriba el cielo pierde su color y el vientre hinchado de la luna nos ilumina. El silencio se rompe bruscamente y las luciérnagas brillan en el espesor de la orilla inundando la escena con su luminoso canto. Las sensaciones vividas, a través de los sonidos del arrozal, quedan recogidas en el libro transmitiendo su propia identidad, haciendo único el lugar ${ }^{6}$.

Comenzamos en Pekín, rumbo al techo del mundo, "el tren del cielo", la última obra de ingeniería ferroviaria realizada, atravesando desiertos y estepas de la mítica ruta de la seda, directos a Lhasa, capital del Tíbet. Casi cuarenta y ocho horas de viaje por las increíbles laderas y montañas a través de la línea férrea más elevada del planeta. Un propósito, realizar una incursión en el budismo tibetano para conocer de cerca sus prácticas espirituales, los lugares sagrados, la vida de los lamas, las diferentes escuelas lamaístas... Así es como nos adentramos en la espiritualidad de la ciudad de Lhasa. Multitudes de peregrinos agitando sus molinillos de oración haciendo la kora alrededor del templo budista Jorkhang. Cánticos, momentos de meditación, sosiego y bullicio; los brillantes colores ondeando en el cielo. La inmensidad del palacio Potala. La cordillera Himalaya. El monte más alto del mundo, el Everest ${ }^{7}$.

Ejemplares únicos como "Hilvanando estelas y Encajes de aire"8 están inspirados allí donde caen las barreras entre el bosque y los sentidos. Japón, las formas planas y sólidas, las tintas al agua de los colores empleados en el teatro, el diseño y la composición, crean imágenes con estilo propio, las denominadas 'imágenes del mundo flotante'. Último objetivo Tokio, las Flores de Edo, donde la diversidad territorial nos arrolla, colinas, rascacielos, bahía, templos, santuarios, museos, barrios, distritos, el área urbana más grande del mundo en términos de población, albergando a más de treinta millones de habitantes. Su civismo y urbanidad resultó impactante” (6).

Como diario emocional del viaje, donde se documentan las impresiones, bajo los conceptos Microcosmos $^{9}$ : la pequeñez como invisibilidad y Macrocosmos ${ }^{10}$ : la escala superlativa como invisibilidad, hace que los libros, pertenecientes a la serie Mente y Materia, adquieran un carácter metafórico y visual. El poema de William Blake, Augurios de la inocencia, lleva el tema al límite, produciendo sus versos una forma de mirar inspiradora: "Ver a un Mundo en un Grano de Arena / Y un Cielo en una Flor Silvestre: / Toma la Infinitud en la palma de tu mano / Y la Eternidad en una hora (7). De este modo, se pretende recrear lo que significa compartir un destino, con la libertad y la flexibilidad necesarias para hacer cada día diferente y así tomar un rol activo en el viaje. Desplazarse en transporte colectivo, compartiendo asiento con la gente del país, alojarse en pequeños hoteles de propiedad familiar y comer en restaurantes locales, proporciona una mayor interacción e integración con el país de destino y hace que todos los gastos del viaje reviertan en las pequeñas economías locales, aportando nuestro granito de arena a su desarrollo. Sin duda el viaje constituye una interesante metáfora para incorporar el tiempo en el libro. (fig. 6) 


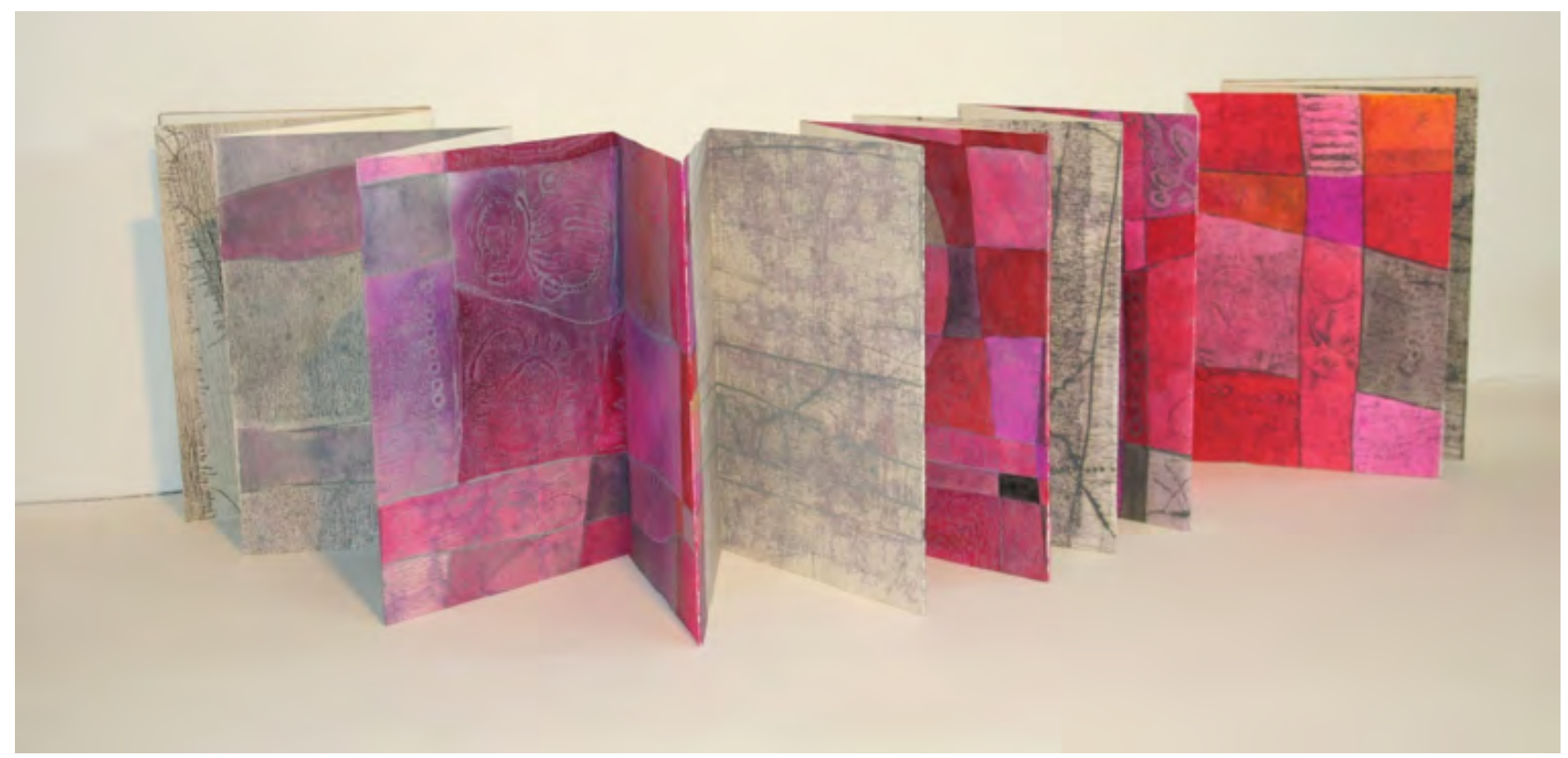

(fig. 6) Microcosmos, 2013

\section{El otro viaje desde la introversión}

Es también necesario dejar registrados una serie de libros que no corresponden al viaje físico tal como lo conocemos, pero como respetan los principios de espacialidad, temporalidad y recogen el pensamiento plástico a modo documental, decidimos pertinente incluirlos como anexo.

Son los diarios íntimos, considerados como tipología particular del libro, donde las narraciones cotidianas de los sentimientos, las emociones, la reflexión, las confesiones... en una palabra, el examen de conciencia, hacen del libro un objeto que se representa a sí mismo. Ese viaje interior requiere de un proceso creativo que no tendrá límites. La propuesta personal funcionará como concepto recreador de las circunstancias y sucesos vividos que rodean los aconteceres personales. "Mente y materia. De lo que produce el amor y la carne"11 se mantiene lejos de ser un diario ilustrado, sino que pretende, a través de un discurso elocuente, narrar la vida con emociones visuales, geometría, luz y color, sondeando los límites de la interioridad a través del formato libro de artista.

Con la misma dimensión de agenda y continuando con el viaje interior, se formaliza 
"Notas y reflexiones sobre herencias, desgarros y cosidos" ${ }^{12}$. Tomando la linealidad y la horizontalidad del formato acordeón, las palabras y las imágenes recrean una lectura intimista, mostrando su contenido, mientras se fragmentan las emociones. La palabra, fuente del acontecer visual del libro, nos narra y documenta cómo repetimos los roles sociales preestablecidos bajo nuestras propias conductas.

Guardado en un estuche esperando ser liberado de su estado de hibernación, se halla la versión original de "Herencias, desgarros y cosidos” (fig. 7). Un proceso metodológico de planificación gráfica sirve de antecedente a una serie de libros donde el pensamiento se concentra como viaje interior, íntimo y personal. Como estrategia de creación y comunicación se emplea el recurso técnico de la estampación simultánea, a partir de la superposición de capas y transparencias, favoreciendo un registro que se utilizará en varios libros. Uno de ellos es "Los huecos de tu piel"13, donde la utilización sistemática de fragmentos de tarlatana como matriz, generará elementos que propician el camuflaje, la envoltura y el ocultamiento.
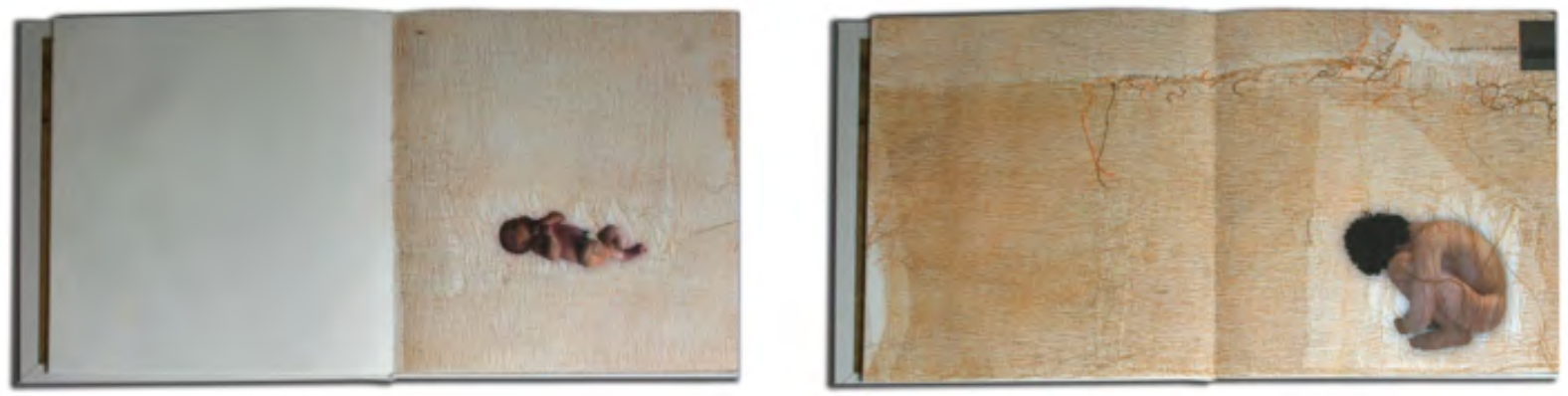

(fig. 7) Herencias, desgarros y cosidos, Madrid, 2011 


\section{A modo de conclusión}

Desde el ámbito del conocimiento del libro, como artista, docente e investigadora, se ha pretendido el acercamiento a una serie de libros auto editados que tienen como temática común el viaje, donde su lectura ha sido transformada en percepción visual.

Estos libros ofrecen una panorámica de dos aspectos importantes incluidos en la tipología del libro de artista. El primero el viaje como tal, donde se tratan aspectos geofísicos y el segundo el viaje interior, siendo el común denominador su carácter autobiográfico. Analizar el viaje narrando su recorrido, tal como lo hemos percibido, nos reconforta, sin embargo, trabajar el interior a partir de parámetros emocionales nos remueve pero nos da claves para seguir creando.

Tras el encuentro con la escritura y la necesidad de distanciarnos para poder concluir el proceso de creación, diremos que la imagen o analogía de viaje y el recorrido direccional de principio a fin que exigen los convencionalismos occidentales para que el libro sea leído de izquierda a derecha, nos permiten incorporar el factor tiempo, partida y regreso, requisito indispensable tanto en el libro como en el viaje. El proceso que implica una comprensión crítica del acto de leer, es codificado a través de la imagen convertida en libro de artista.

Para finalizar queremos destacar la importancia de los cuadernos, utilizados para expresar semánticamente, conceptualmente o de manera metafórica lo observado. Son los instigadores de una ficción poética que se transcribirá, en la serenidad del taller, en libros de artista únicos, sobrepasando el concepto de cuaderno de notas y accediendo a una dimensión más amplia, que contempla la forma libro como una totalidad. 
Revista de Estudios en Sociedad, Artes y Gestión Cultural

www.terciocreciente.com http://revistaselectronicas.ujaen.es/index.php/RTC
Estudio

\section{Notas}

1. Nueva línea troncal, 2008, es un conjunto secuenciado y más bien sistemático de observaciones y dibujos realizados a través de las ventanas del Shinkansen. El cuaderno de viaje contiene anotaciones sobre patrimonio cultural, fortalezas, jardines, templos budistas, sintoístas, ryokanes, casas de té.... El contenido es secuenciado porque va transcribiéndose a lo largo del viaje, y es sistemático porque el proceso de dibujar se basa en ver, observar y almacenar en la memoria para el futuro. Cuando se materialice en libro, el conocimiento visual guardado, reproducirá la esencia de lo más interesante que se encontró en la realidad observada, los rasgos más significativos. (fig. 1)

2. “Japón siempre fue uno de mis destinos soñados. Largas horas he pasado contemplando los brillantes colores del Kabuki, las escenas teatrales y los retratos de los actores populares en papeles dramáticos. Las estampas de bellas mujeres, especialmente las cortesanas del barrio de Yoshiwara, anunciadoras del mundo de las geishas y prostitutas. Escenas con los episodios heroicos de la historia japonesa relatada a través de sus guerreros, sacerdotes y samuráis. La vida nocturna en los concurridos barrios de madera, donde el ir y venir de artistas y damas llenan de intriga la escena. Los elaborados kimonos, la ceremonia del té. Las treinta y seis vistas del Monte Fuji, los paisajes puros, las flores, los pájaros... en una palabra, mi fascinación por el Ukiyo-e, esas estampas creadas para el gran público, de carácter efímero y semejantes a las tarjetas postales” (4).

3. En el jardín te esperaré, 2014. Collagraph iluminado a mano, monotipo 36 x $25 \mathrm{~cm}$ [libro] 36 x $300 \mathrm{~cm}$. a sangre [imagen]. Ejemplar único

4. El bosque donde habito, 2013. Ocho monotipos, collagraph iluminado a mano, $62 \mathrm{x} 62 \mathrm{~cm}$ [libro] $60 \mathrm{x}$ $60 \mathrm{~cm}$. a sangre [imagen] sobre papel Fabriano. Ejemplar único

5. El cementerio de los niños, 2013. Collagraph y dibujo, 35 x $25 \mathrm{~cm}$ [libro], 35 x $200 \mathrm{~cm}$. a sangre [imagen] papel encolado sobre cartón. Ejemplar único donde se relatan lugares alejados de los circuitos turísticos; el paisaje expandido atrapa al viajero en su panorámica.

6. Los sonidos del arrozal, 2009_10. Collagraph iluminado a mano, 11 x $32 \mathrm{~cm}$ [libro], 31,5 x 236,5 cm. a sangre [imagen]. Ejemplar único

7. Historias silenciadas, 2011. Collagraph iluminado a mano, 19 x $25 \mathrm{~cm}$ [libro], 19 x $260 \mathrm{~cm}$. a sangre [imagen]. Papel chino encolado sobre papel. Ejemplar único

8. Hilvanando estelas, 2009. Grabado y dibujo, 24 x $16 \mathrm{~cm}$ [libro], 24 x $304 \mathrm{~cm}$. a sangre [imagen]. Papel chino encolado sobre papel.

Encajes de aire, 2008. Collagraph iluminado a mano, 19 x $25 \mathrm{~cm}$ [libro], 19 x $260 \mathrm{~cm}$. a sangre [imagen]. Papel chino encolado sobre papel. 
9. Mente y materia, Microcosmos, 2013. Collagraph e impresión digital, 19 x $25 \mathrm{~cm}$ [libro], 19 x $260 \mathrm{~cm}$. a sangre [imagen]. Papel chino encolado sobre papel. Ejemplar único

10. Mente y materia, Macrocosmos, 2013. Collagraph e impresión digital, 19 x 25 cm [libro], 19 x 260 $\mathrm{cm}$. a sangre [imagen]. Papel chino encolado sobre papel. Ejemplar único

11. Mente y materia. De lo que produce el amor y la carne, 2012. Impresión digital, 13 x $21 \mathrm{~cm}$ [libro], 22 [páginas], 11 ejemplares y dos pruebas de estado. Edición encuadernada en Álbum Japonés de Moleskine. ISBN: 978-84-615-9834-2

12. Notas y reflexiones sobre Herencias_desgarros y cosidos, 2011. Impresión digital, 13 x $21 \mathrm{~cm}$ [libro], 22 [páginas], 11 ejemplares y dos pruebas de estado. ISBN: 978-84-615- 3105-9

Edición encuadernada en Álbum Japonés de Moleskine proponiendo continuidad a la idea de diario íntimo, la introspección. Corresponde a la edición digital aclaratoria del libro Herencias_desgarros y cosidos; en él se exponen las claves para el entendimiento y la reflexión.

13. Los huecos de tu piel, 2010_11. Monotipo, 36 x 25,3 cm [libro] 36 x $324 \mathrm{~cm}$. a sangre [imagen] sobre papel de arroz japonés. Ejemplar único

\section{Referencias}

(1). El libro como... Catálogo exposición Biblioteca Nacional de España comisariada por Magda Polo Pujadas. 26.09.2012 - 13.01.2013 [Consultado el 8 de octubre de 2016 de http:// www.bne.es/es/Actividades/Exposiciones/Exposiciones/exposiciones2012/Librocomo. html]

(2). Ibíd., [Consultado el 8 de octubre de 2016 de http://www.bne.es/es/Actividades/ Exposiciones/Exposiciones/exposiciones2012/Librocomo.html]

(3). Muñoz Molina, Antonio. La fraternidad de los cuadernos. El País, 4 de Enero de 2014. [Consultado el 7 de Julio de 2015 y comprobado el 8 de octubre de 2016 de http://cultura. elpais.com/cultura/2013/12/30/actualidad/1388427034_678047.html]

"Dibujar es aprender a mirar; es adiestrar los canales neurológicos que conectan la pupila, el cerebro, la mano. El dibujo es manejar la herramienta simple y prodigiosa del lápiz, permanecer alerta a las variaciones sutiles en la materialidad del papel, su resistencia, su suavidad, su aspereza. Yo llevo siempre conmigo un cuaderno, y no me separo de él hasta que no he llenado todas sus páginas, pero no hay casi nada que me dé más envidia que los cuadernos de los dibujantes. Los míos son cuadernos monótonos en los que no hay nada más que palabras, si acaso la entrada de algún concierto, o la de un museo, o una hoja o 
un tallo de hierba. En los cuadernos de los dibujantes están las imágenes del mundo, el diario visual y el collage tangible de la vida, la crónica instantánea de la mirada.”

(4). Su referencia está en el libro Aguilar Moreno, Marta. Japón, Tras la huella de Kunisada. Libro de viaje editado por Arkhagay Tours S.L. Colección Ediciones El Paso del Noroeste, Madrid, 2009, p. 7

(5). Aguilar Moreno, Marta. El libro de artista como instrumento de inclusión social, Cuaderno sobre el libro, LAMP 03. Edita Grupo de Investigación El libro de artista como materialización del pensamiento, 2014. En colaboración con la Asociación APURVA, se decidió proponer, como actividad autónoma para todos los alumnos, universitarios y usuarios en tránsito, la realización de un libro de artista en el cual el protagonismo recaería en el imaginario de la casa, las formas de ocupación y construcción del espacio en nuestra vida cotidiana. Para ello se impartió el taller Donde habito: imaginarios y construcción del espacio a través del dibujo y la fotografía, donde se aplicaron los principios básicos de la metodología de la fotografía participativa, como herramienta de expresión y comunicación de experiencias y realidades sobre diferentes aspectos de la vida cotidiana.

(6). Aguilar Moreno, Marta. Japón, Tras la huella de Kunisada. Op. Cit., p. 8

(7). Blake, William. Augurios de la inocencia [Consultado el 9 de Julio de 2015 y comprobado el 8 de octubre de 2016 de http://archivodepoetica.blogspot.com.es/2009/07/augurios-dela-inocencia-william-blake.html]

\section{Bibliografía}

Catálogo VV.AA. (2006). Visiones del Guadarrama. Miguel Ángel Blanco y los artistas pioneros de la sierra. Madrid, edita La Casa Encendida.

Catálogo VV.AA. (2013). Abierto todo el día. Los cuadernos de Isidro Ferrer \& Pep Carrió. Valencia, edita Grupo de Investigación Unit_edición experimental e interactiva.

Diego, E. (2014). Rincones de postales. Turismo y hospitalidad. Madrid, Cuadernos Arte Catédra.

Haskell, D.G. (2012). En un metro de bosque, un año observando la naturaleza, traducido al castellano en 2014 por Turner Publicaciones (edición original en inglés).

Rilke, R.M. (1981). Los cuadernos de Malte Laurids Brigge. Madrid, Alianza. 
Revista de Estudios en Sociedad, Artes y Gestión Cultural

ISSN: 2340-9096

DOI: $10.17561 /$ rtc.mextra1.10 www.terciocreciente.com

http://revistaselectronicas.ujaen.es/index.php/RTC
Monográfico Extraordinario I

Julio 2017

\section{Estudio}

